\title{
Antithrombotic therapy in acute ischaemic stroke: an overview of the completed randomised trials
}

\author{
P A G Sandercock, A G M van den Belt, R I Lindley, J Slattery
}

Abstract

A formal statistical overview of all truly randomised trials was undertaken to determine whether antithrombotic therapy is effective and safe in the early treatment of patients with acute stroke. There were 15 completed randomised controlled trials of the value of early antithrombotic treatment in patients with acute stroke. The regimes tested in acute presumed or confirmed ischaemic stroke were: heparin, 10 trials with 1047 patients: oral anticoagulants, one trial with 51 patients: antiplatelet therapy, three trials with 103 patients. Heparin was tested in one trial with 46 patients with acute haemorrhagic stroke. Outcome measures were deep venous thrombosis (confirmed by $\mathbf{I}^{125}$ scanning or venography), pulmonary embolism, death from all causes, haemorrhagic transformation of cerebral infarction, level of disability in survivors. In patients with acute ischaemic stroke, allocation to heparin was associated with a highly significant $81 \%$ (SD 8, 2p $<0.00001$ ) reduction in deep venous thrombosis detected by $I^{125}$ fibrinogen scanning or venogram. Only three trials systematically identified pulmonary emboli, which occurred in $6 / 106(5 \cdot 7 \%)$ allocated control vs $3 / 132(2 \cdot 3 \%)$ allocated heparin, a nonsignificant $58 \%$ reduction (SD $45 \cdot 7,2 p>$ $0 \cdot 1)$. There were relatively few deaths in the trials in patients with presumed ischaemic stroke: $94 / 485(19 \cdot 4 \%)$ among patients allocated to the control group vs $79 / 497(15 \cdot 9 \%)$ among patients who were allocated heparin. The observed $18 \%$ (SD 16) reduction in the odds of death was not statistically significant. The least biased estimate of the effect of treatment on haemorrhagic transformation of the cerebral infarct (HTI) comes from trials where all patients were scanned at the end of treatment, irrespective of clinical deterioration; using this analysis, haemorrhagic transformation occurred in 7/102 $(6.9 \%)$ control vs $8 / 106(7 \cdot 5 \%)$ treated, a non-significant $12 \%$ increase (SD 56,2 p $>0 \cdot 1)$. These data cannot exclude the possibility that heparin substantially increases the risk of HTI. No data on disability in survivors could be obtained. Early heparin treatment might be associated with substantial reductions in deep venous thrombosis (and probably also pulmonary embolism) and possibly a one fifth reduction in mortality (equivalent to the avoidance of $20-40$ early deaths per thousand patients treated). However, the data were wholly inadequate on safety, particularly on the risk of haemorrhagic transformation of the infarct and on the hazards of heparin therapy in patients with known intracerebral haemorrhage. The trials of oral anticoagulants (15 deaths among 57 patients) and antiplatelet therapy (two deaths among 103 patients) were too small to be informative. Much larger randomised trials-comparing aspirin, heparin and the combination of both drugs against control-in patients with acute ischaemic stroke are justified (and several are now planned or underway).

\section{$(\mathcal{F}$ Neurol Neurosurg Psychiatry 1993;56:17-25)}

Each year, there are about 1.5 million new strokes per year in the USA and in the European Community. ${ }^{1-3}$ Eighty five per cent of strokes are ischaemic, ${ }^{3}$ so over the next decade, there will be some 12.8 million patients with acute ischaemic stroke, for whom antithrombotic treatment might be considered. Of these patients, about 1.5 million will be dead within two weeks of their stroke. Many will survive, but be dependent on other people for help with activities of daily living. Aspirin and heparin are simple, practicable antithrombotic regimes which could be given to almost every patient with acute ischaemic stroke. If these two treatments were proven to be effective and safe, the potential scale of their use is enormous.

Antithrombotic drugs yield substantial clinical benefits in the early treatment of unstable angina and acute myocardial infarction. ${ }^{4-10}$ For example, in acute myocardial infarction, one month's oral aspirin reduces early mortality by one fifth ${ }^{4}$ and one or two weeks' heparin can reduce one month mortality by about one tenth. ${ }^{511}$ If the widespread early use of these treatments in patients with acute ischaemic stroke (cerebral infarction) were associated with similar benefits, perhaps 300000 early deaths would be avoided over the next decade in Europe and USA. In addition to improving survival, early antithrombotic treatment with aspirin or heparin, by reducing the volume of infarcted cerebral tissue, avoiding early recurrence of thromboembolic stroke and reducing venous thromboembolic complications might reduce neurological disability in survivors. $^{12-14}$ 
This paper is a formal statistical overview of all the randomised trials of antithrombotic treatment in patients with acute ischaemic stroke. Our aim was to determine whether there is clear evidence that treatment is beneficial and, if not, whether a very large scale trial is justifiable. ${ }^{15-17}$

\section{Methods}

We sought to identify all truly randomised trials of early treatment with antithrombotic agents in patients with acute stroke. Thus trials in which allocation to treatment or control group was not truly randomised (that is, alternating, or based on date of birth or hospital number) were not included, since foreknowledge of treatment allocation might lead to biased treatment allocation. Trials which randomised patients more than seven days after onset of the stroke, and trials in patients with only transient ischaemic attacks were excluded, because this review was confined to early treatment of acute stroke. The anticoagulant agents considered were: standard unfractionated heparin, low molecular weight (LMW) heparin, and oral anticoagulants. We sought trials of the antiplatelet agents: aspirin, ticlopidine, sulphinpyrazone, suloctidil, dipyridamole, indobufen, flurbiprofen and the combination of aspirin and dipyridamole. Relevant randomised trials were identified by computer aided search (MEDLINE), by conversation with colleagues (particularly those who had coordinated such studies), by scrutiny of the reference lists of trials and review articles, by inquiry of various manufacturers of anticoagulants and by searching the trials register held by the Antiplatelet Trialists' Collaboration (APT). ${ }^{17} \mathrm{We}$ aimed to extract from each trial the number of patients originally allocated to each treatment group, and in each treatment group, the number of patients: a) with objective evidence of the occurrence of deep venous thrombosis (DVT) detected by systematic 125-I-fibrinogen scanning or systematic radiograph contrast venography during the scheduled treatment period; b) with at least one confirmed pulmonary embolus; c) who died from any cause during the scheduled follow up period (generally longer than the scheduled period of drug treatment); d) who died from any cause during the scheduled treatment period; e) with haemorrhagic transformation confirmed by routine CT scanning; f) with recurrent stroke by the end of the scheduled study follow up period; $g$ ) who were dead or dependent on help from other people in activities of daily living at 6 months after the stroke. Data on the number of patients with each outcome event, by allocated treated group, irrespective of compliance, and whether or not the patient was subsequently considered ineligible or otherwise excluded from treatment or follow up were sought to allow an "intention to treat" analysis.

If these data were not available in publications, further data were sought by correspondence with the authors. Data on whether CT scanning was performed before randomisation were also sought.

\section{Statistical analysis}

The statistical overview was performed by the standard method described by Yusuf and Peto. ${ }^{16-18}$ For each trial, the number of subjects in whom a particular adverse event was observed in the treatment group $(\mathrm{O})$ is contrasted with the number that, if treatment really had no effect, would have been expected (E) on the basis of the overall experience in the treatment and control groups combined. If treatment were effective, the grand total (GT) should be negative. If, however, treatment were wholly without effect, the GT would differ only randomly from zero (with variance total [VT] equal to the sum of the individual variances in the separate $\mathrm{O}-\mathrm{E}$ values, and with the standard deviation [SD] equal to the square root of the total variance). Formal statistical tests assessing whether treatment is without effect involve the calculation of $Z$, the number of standard deviations by which the GT differs from zero ( $Z=G T / S D)$, and comparison of $Z$ with tables of the standard normal distribution. (Thus, for example, a favourable result with $Z=-1.96$ suggests a $P$ value of about 0.05 .) (All $P$ values are twosided.) An estimate of the typical percentage reduction in the odds ( $R$ ) of an adverse event occurring among treated patients compared with controls can be calculated with use of the approximate formula $R=100-100$ expected (Z/SD), with $95 \%$ confidence limits $100-100$ expected (Z/SD $\pm 1 \cdot 96 / S D)$, and the standard deviation of $R$ may be estimated by $-R / Z$. Tests for heterogeneity of the effects of treatment between several different trials (or categories of trial) can also be performed. For each trial in which the variance, $\mathrm{V}$, of $\mathrm{O}-\mathrm{E}$ is not zero, the quantity $(\mathrm{O}-\mathrm{E})^{2} / \mathrm{V}$ can be calculated, and all such quantities, one per trial, added up. Subtraction of $(\mathrm{GT})^{2} /(\mathrm{VT})$ from this total provides an approximate chi-square test statistic, with one fewer degree of freedom than the number of such trials. An overview of many trial results assumes not that the real effects of treatment are all exactly the same size in the different trials but merely that most or all of the real effects probably point in the same general direction.

\section{Results}

Twenty one trials were identified (tables 1 and 2). Six trials are either planned or are still in progress and results are not expected to be available for some time. This review is of the remaining fifteen ${ }^{19-33}$ completed trials.

Trials of heparin and oral anticoagulant drugs in acute stroke

We have identified 11 controlled trials of anticoagulant drugs in patients with acute ischaemic stroke which compared anticoagulant effects with control. The agents were: standard heparin (six trials), LMW heparin (four trials), oral anticoagulants (one trial). One trial in patients with haemorrhagic stroke compared standard heparin with control. Details of the regimes are in the tables. The scheduled period of acute antithrombotic 
Table 1 Randomised trials of heparin or oral anticoagulants in acute stroke

\begin{tabular}{|c|c|c|c|c|c|c|c|c|c|c|}
\hline $\begin{array}{l}\text { Study } \\
\text { Author/trial name }\end{array}$ & $\begin{array}{l}\text { Number of } \\
\text { patients }\end{array}$ & $\begin{array}{l}\text { Start of } \\
\text { treatment } \\
\text { within (hrs) } \\
\text { of stroke } \\
\text { onset }\end{array}$ & $\begin{array}{l}\text { CT scan } \\
\text { before } \\
\text { trial } \\
\text { entry } \\
(\%)\end{array}$ & $\begin{array}{l}\text { Scheduled } \\
\text { duration of } \\
\text { treatment } \\
\text { (days) }\end{array}$ & $\begin{array}{l}\text { Scheduled } \\
\text { duration of } \\
\text { clinical } \\
\text { follow up } \\
\text { (months/days) }\end{array}$ & $\begin{array}{l}\text { Active } \\
\text { treatment }\end{array}$ & $\begin{array}{l}\text { Control } \\
\text { treatment }\end{array}$ & Route & Dose & Dose interval \\
\hline \multicolumn{11}{|c|}{$\begin{array}{l}\text { Acute presumed ischaemic stroke: completed trials } \\
\text { Standard Heparin Trials }\end{array}$} \\
\hline $\begin{array}{l}\text { Duke }^{19} \\
\text { CESG }^{20} \\
\text { McCarthy }^{21} \\
\text { McCarthy }^{22} \\
\text { Czechanowski }^{23} \\
\text { Duke }^{24}\end{array}$ & $\begin{array}{l}225 \\
45 \\
305 \\
32 \\
107 \\
65\end{array}$ & $\begin{array}{l}48 \\
48 \\
48 \\
48 \\
120 \\
48\end{array}$ & $\begin{array}{l}100 \\
100 \\
0 \\
0 \\
0 \\
81^{8}\end{array}$ & $\begin{array}{l}7 \\
10 \\
14 \\
14 \\
14 \\
7\end{array}$ & $\begin{array}{l}12 \text { months } \\
14 \text { days } \\
3 \text { months } \\
1 \text { month } \\
14 \text { days } \\
12 \text { months }\end{array}$ & $\begin{array}{l}\text { Heparin } \\
\text { Heparin } \\
\text { Heparin } \\
\text { Heparin } \\
\text { H-DHE } \\
\text { Heparin }\end{array}$ & $\begin{array}{l}\mathbf{P} \\
\mathbf{N} \\
\mathbf{N} \\
\mathbf{N} \\
\mathbf{P} \\
\mathbf{P}\end{array}$ & $\begin{array}{l}\text { iv } \\
\text { iv } \\
\text { sc } \\
\text { sc } \\
\text { sc } \\
\text { sc }\end{array}$ & $\begin{array}{l}\text { adjusted" }^{*} \\
\text { adjusted } \\
5000 \mathrm{U} \\
5000 \mathrm{U} \\
5000 \mathrm{U}+0 \cdot 5 \mathrm{mg} \\
5000 \mathrm{U}\end{array}$ & $\begin{array}{l}\text { cont inf } \\
\text { cont inf } \\
8 \mathrm{hrs} \\
8 \mathrm{hrs} \\
12 \mathrm{hrs} \\
8 \mathrm{hrs}\end{array}$ \\
\hline \multicolumn{11}{|c|}{ LMW Heparin Trials } \\
\hline $\begin{array}{l}\text { Turpie } \\
\text { Prins }^{26} \\
\text { Sandset }^{27} \\
\text { Elias }^{28}\end{array}$ & $\begin{array}{l}75 \\
60 \\
103 \\
30\end{array}$ & $\begin{array}{l}168 \\
72 \\
72 \\
48\end{array}$ & $\begin{array}{l}100 \\
100 \\
100 \\
100^{\mathrm{s}}\end{array}$ & $\begin{array}{l}14 \\
14 \\
14 \\
14\end{array}$ & $\begin{array}{l}3 \text { months } \\
14 \text { days } \\
1 \text { month } \\
14 \text { days }\end{array}$ & $\begin{array}{l}\text { LMWH } \\
\text { LMWH } \\
\text { LMWH } \\
\text { LMWH }\end{array}$ & $\begin{array}{l}\mathbf{P} \\
\mathbf{P} \\
\mathbf{P} \\
\mathbf{N}\end{array}$ & $\begin{array}{l}\text { sc } \\
\text { sc } \\
\text { sc } \\
\text { sc }\end{array}$ & $\begin{array}{l}750 \mathrm{aXaU} \\
2500 \mathrm{aXaU} \\
3000-5500 \mathrm{aXaU} \\
15,000 \mathrm{aXaU}\end{array}$ & $\begin{array}{l}12 \mathrm{hrs} \\
12 \mathrm{hrs} \\
24 \mathrm{hrs} \\
24 \mathrm{hrs}\end{array}$ \\
\hline $\begin{array}{l}\text { Oral Anticoagulants } \\
\text { Marshall }^{29}\end{array}$ & 51 & 72 & 0 & 21 & 6 months & $\begin{array}{l}\text { Phen } \\
+24 \text { hrs } \mathrm{H}\end{array}$ & $\mathbf{N}$ & $\mathbf{o}$ & adjusted $^{\mathbf{c}}$ & $24 \mathrm{hrs}$ \\
\hline \multicolumn{11}{|c|}{ Acute Presumed Ischaemic Stroke: planned/in progress } \\
\hline $\begin{array}{l}\text { TOAST } \\
\text { UK ORG10172 }\end{array}$ & $\begin{array}{l}1300^{\mathrm{d}} \\
180^{\mathrm{d}}\end{array}$ & $\begin{array}{l}24 \\
120\end{array}$ & $\begin{array}{l}100 \\
100\end{array}$ & $\begin{array}{l}7 \\
8-10\end{array}$ & $\begin{array}{l}3 \text { months } \\
12 \text { weeks }\end{array}$ & $\begin{array}{l}\text { LMWH } \\
\text { LMWH }\end{array}$ & $\begin{array}{l}\mathbf{P} \\
\mathbf{P}\end{array}$ & $\begin{array}{l}\text { sc } \\
\text { sc } \\
\text { or }\end{array}$ & $\begin{array}{l}\text { Adjusted }^{e} \\
750 \mathrm{aXaU} \\
1250 \mathrm{aXaU}\end{array}$ & $\begin{array}{l}24 \mathrm{hrs} \\
12 \mathrm{hrs} \\
24 \mathrm{hrs}\end{array}$ \\
\hline $\begin{array}{l}\text { International } \\
\text { Stroke Trial }\end{array}$ & $20000^{d}$ & 48 & $100^{\mathrm{h}}$ & 14 & 6 months & $\begin{array}{l}\text { Heparin } \\
\text { Heparin } \\
\text { Heparin } \\
\text { Aspirin } \\
\text { Heparin+ } \\
\text { Aspirin } \\
\text { Aspirin } \\
\text { LMWH }\end{array}$ & $\begin{array}{l}\mathbf{N} \\
\mathbf{N} \\
\mathbf{N} \\
\mathbf{N} \\
\mathbf{N} \\
\mathbf{P}\end{array}$ & $\begin{array}{l}\text { sc } \\
\text { sc } \\
\text { sc } \\
\text { o/pr } \\
\text { sc } \\
\text { o/pr } \\
\text { o/pr } \\
\text { sc }\end{array}$ & $\begin{array}{l}5000 \mathrm{U} \\
12500 \mathrm{U} \\
5000 \mathrm{U} \\
300 \mathrm{mg} \\
12500 \mathrm{U} \\
300 \mathrm{mg} \\
300 \mathrm{mg} \\
7500 \mathrm{aXaU}\end{array}$ & $\begin{array}{l}12 \mathrm{hrs} \\
12 \mathrm{hrs} \\
12 \mathrm{hrs} \\
24 \mathrm{hrs} \\
12 \mathrm{hrs} \\
24 \mathrm{hrs} \\
24 \mathrm{hrs} \\
12 \mathrm{hrs}\end{array}$ \\
\hline \multicolumn{11}{|c|}{ Acute Haemorrhagic Stroke: completed trial } \\
\hline
\end{tabular}

H: standard heparin; H-DHE: standard heparin + Dihydroergotamine; LMWH: low molecular weight heparin; Phen: Phenindione; aXaU: anti-factor Xa units; P: placebo; N: No treatment; iv: intravenous; cont inf: continuous infusion; sc: subcutaneous; ns: not stated.

placebo; N: No treatment; iv: intravenous; cont inf: continuous infusio

Adjusted dose to keep partial thromboplastin time $50-70$ seconds
bAdjusted dose to keep partial thromboplastin ratio $1 \cdot 5-2 \cdot 5 x$ pretreatment level.

Adjusted dose to keep partial thromboplastin ratio $1 \cdot 5$

"Adjusted dose to keep prothrom

Treatment of acute stroke trial (TOAST). Adjusted dose therapy

'This trial has a $3 \times 2$ factorial design

Percentage with CT scan within 48 hours of trial entry

${ }^{n} \mathrm{CT}$ scan not mandatory before randomisation, but should be obtained quickly thereafter if possible.

Table 2 Randomised trials of antiplatelet agents in acute ischaemic stroke

\begin{tabular}{|c|c|c|c|c|c|c|c|c|c|}
\hline $\begin{array}{l}\text { Study } \\
\text { Author/trial name }\end{array}$ & $\begin{array}{l}\text { Number of } \\
\text { patients }\end{array}$ & $\begin{array}{l}\text { Start of } \\
\text { treatment } \\
\text { within (hrs) } \\
\text { of stroke } \\
\text { onset }\end{array}$ & $\begin{array}{l}\text { Scheduled } \\
\text { duration of } \\
\text { treatment } \\
\text { (days) }\end{array}$ & $\begin{array}{l}\text { Scheduled } \\
\text { duration of } \\
\text { clinical } \\
\text { follow up } \\
\text { (months/days) }\end{array}$ & $\begin{array}{l}\text { Active } \\
\text { treatment }\end{array}$ & $\begin{array}{l}\text { Control } \\
\text { treatment }\end{array}$ & Route & Dose & Dose interval \\
\hline $\begin{array}{l}\text { Completed Trials } \\
\text { Utsumi }^{31} \\
\text { Joseph }^{32}\end{array}$ & $\begin{array}{l}29 \\
44\end{array}$ & $\begin{array}{l}\text { ns } \\
240\end{array}$ & $\begin{array}{l}\text { ns } \\
\text { ns }\end{array}$ & $\begin{array}{l}\text { N/A } \\
\text { N/A }\end{array}$ & $\begin{array}{l}\text { Ticl } \\
\text { Asp+dip }\end{array}$ & $\stackrel{\mathbf{P}}{\mathbf{N}}$ & $\begin{array}{l}\mathbf{0} \\
\mathbf{0}\end{array}$ & $\begin{array}{l}300 \mathrm{mg} \\
\pm 330 \mathrm{mg} \text { Asp } \\
\pm 180 \mathrm{mg} \text { Dip }\end{array}$ & $\begin{array}{l}\text { ns } \\
\text { ns }\end{array}$ \\
\hline $\begin{array}{l}\text { Ciuffetti }{ }^{33} \\
\text { Planned/In Progress }\end{array}$ & 30 & 12 & 21 & N/A & Ticl & $\mathbf{P}$ & o & $250 \mathrm{mg}$ & $12 \mathrm{hrs}$ \\
\hline $\begin{array}{l}\text { Britton } \\
\text { MAST Italy }\end{array}$ & $\begin{array}{l}300^{\circ} \\
1500^{*}\end{array}$ & $\begin{array}{l}\text { ns } \\
6\end{array}$ & $\begin{array}{l}\text { ns } \\
10\end{array}$ & $\begin{array}{l}\text { ns } \\
6 \text { months }\end{array}$ & $\begin{array}{l}\text { Aspirin } \\
\text { Aspirin } \\
\text { Str }\end{array}$ & $\begin{array}{l}\mathrm{P} \\
\mathbf{N} \\
\text { iv }\end{array}$ & $\begin{array}{l}\text { o } \\
\text { o/or } \\
\text { iv } \\
1 \cdot 5 \mathrm{MU}\end{array}$ & $\begin{array}{l}325 \mathrm{mg} \\
350 \mathrm{mg} \\
100 \mathrm{mg} \\
\text { One dose only }\end{array}$ & $\begin{array}{l}24 \mathrm{hrs} \\
24 \mathrm{hrs}\end{array}$ \\
\hline $\begin{array}{l}\text { International Stroke Trial } \\
\text { National Study, China }\end{array}$ & $\begin{array}{l}20000 \\
20000^{d}\end{array}$ & $\begin{array}{l}\text { See table } 1 \\
48\end{array}$ & $\begin{array}{l}\text { details } \\
100\end{array}$ & 35 days & Aspirin & $\mathbf{P}$ & o & $325 \mathrm{mg}$ & $24 \mathrm{hrs}$ \\
\hline
\end{tabular}

Ticl: Ticlopidine; Dip: Dipyridamole; P: Placebo; N: No treatment; o: oral; iv: intravenous; ns: not stated; N/A: not available; Str: Streptokinase

Planned number of patients

- Patients are allocated to one of four treatment groups in a $2 \times 2$ factorial design: placebo, aspirin, streptokinase, and aspirin and streptokinase.

treatment ranged from six to 21 days (mean 12 days). The scheduled period of clinical follow up varied from 1-12 months. Six trials routinely performed CT in all patients before randomisation, ${ }^{1920} 25-28$ one trial performed $\mathrm{CT}$ in most patients, ${ }^{24}$ three trials performed CT in almost none ${ }^{21-23}$ and one trial was undertaken before CT scanning was introduced. $^{29}$

a) Effect of heparin on deep venous thrombosis Two trials did not report data on deep venous thrombosis (DVT). ${ }^{1929}$ Nine trials, all comparing heparin with placebo or open control, systematically sought to determine the effect of treatment on the occurrence of (DVT) detected by systematic $I^{125}$ fibrinogen scanning or systematic radiographic contrast venography; eight trials were in patients with ischaemic stroke $^{21-28}$ and one was in patients with haemorrhagic stroke. ${ }^{30}$ In trials of heparin in ischaemic and haemorrhagic stroke, treatment was associated with a highly significant $79 \%$ (SD 8) $2 p<0.00001$ reduction in the odds of confirmed DVT in the scheduled treatment period (fig 1).

There was no clear evidence that reductions in confirmed DVT were importantly different between: patients with ischaemic stroke and patients with haemorrhagic stroke; patients with adjusted dose intravenous heparin, low dose subcutaneous heparin or LMW heparin; when DVT was detected by venography and $I^{125}$ fibrinogen scanning (fig 1 ). 
Figure 1 Apparent effect on deep venous thrombosis detected by systematic $I^{125}$ fibrinogen scanning or by systematic venography in trials among patients with ischaemic stroke and one trial in haemorrhagic stroke. The stratified ratio of the odds of an event in the treatment group to that in the control group it is plotted for each trial (black square: area proportional to the amount of

information contributed); with its $99 \%$ confidence interval (horizontal line). The presence of a black square to the left of the solid vertical line suggests benefit (but this benefit is significant at the level of $2 p<0.01$ ) only if the entire confidence interval is to the left of the solid vertical line. An overview of all of the trial results (and its $95 \%$ confidence limit) is represented by a black diamond beside which is the reduction in the overall incidence in those trials.

Figure 2 Apparent effect on pulmonary embolism.
For explanation of symbols and conventions, see legend to fig 1 .

\section{Heparin in acute stroke}

HEPARIN versus CONTROL: deep vein thrombósis

\begin{tabular}{|c|c|c|c|c|c|}
\hline $\begin{array}{c}\text { Trials } \\
\text { anabyeed }\end{array}$ & $\begin{array}{l}\text { Evente } \\
\text { Heparin }\end{array}$ & $\begin{array}{l}\text { atients } \\
\text { Control }\end{array}$ & $\begin{array}{l}\text { Stratified } \\
\text { (O-E) Variance }\end{array}$ & $\begin{array}{l}\text { Odde Ratlo and CL } \\
\text { (Heparin : Control) }\end{array}$ & $\begin{array}{l}\text { Odds } \\
\text { reduction } \\
\text { (sd) }\end{array}$ \\
\hline
\end{tabular}

\section{ACUTE PRESUMED ISCHAEMIC STROKE:}

\section{DETECTION METHOD: I $^{125}$ fibrinogen leg scan}

$$
\text { McCarthy } 21
$$

McCarthy 22

Czechanowski ${ }^{23}$

$32 / 144 \quad 117 / 16$

Czechanowskí

2/16 12/16

$11 / 54 \quad 23 / 53$

$0 / 35$

- Subtotal: Standard heparin

$45 / 249 \quad 155 / 260 \quad-51 \cdot 1$

Turpie $^{25}$

Prins 26

$2 / 50$

$6 / 30$

$7 / 25 \quad-4 \cdot 0$

$15 / 30 \quad-4.5$

Elias $^{28}$

$0 / 15$

$12 / 15$

$8 / 95$

$34 / 70$

$-6.0$

- Subtotal: LMW Heparin

$-14 \cdot 5$

- Total: Heparin I $^{125}$ trials

$53 / 344$

$189 / 330$

$-65 \cdot 6$

DETECTION METHOD: venography

$$
\text { Sandset }{ }^{27}
$$

$15 / 52$

$17 / 5$

$-1 \cdot 2 \quad 5 \cdot 6$

Total: Iechaemic stroke trials 68/396

$206 / 381$

$-66 \cdot 8$

ACUTE HAEMORRHAGIC STROKE:

Dickmann $^{30}$

$8 / 23$

Total: All trials

$76 / 419$

216/404
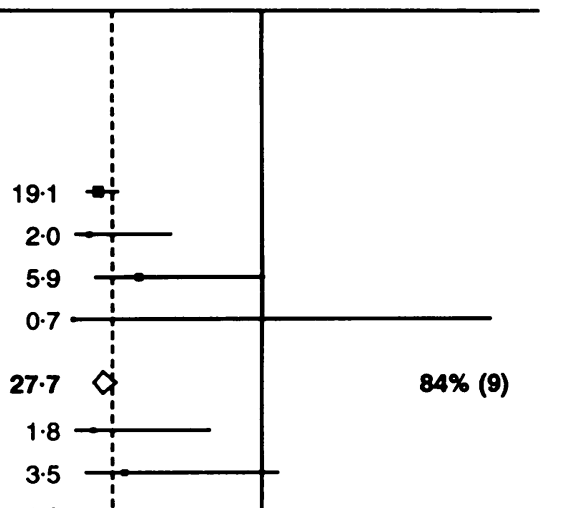

1.9

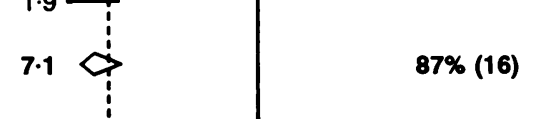

34.8 85\% (8)

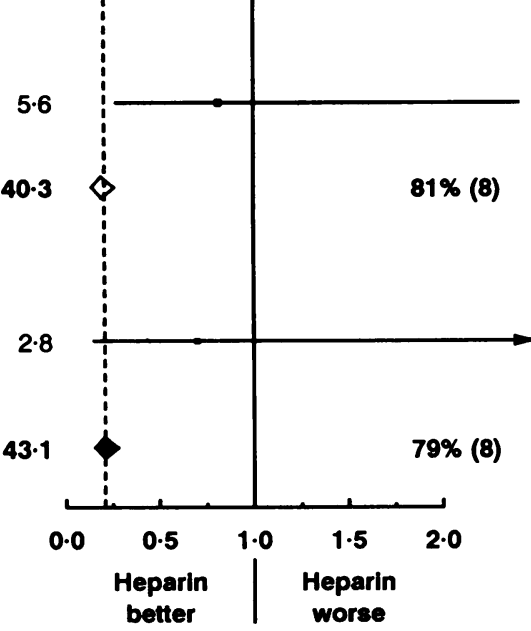

Treatment effect $2 P<0.00001$ 
Figure 3 Apparent effect on mortality of heparin or warfarin on trials in patients with ischaemic or haemorrhagic stroke. For explanation of symbols and conventions, see legend to fig 1 .

Heparin or oral anticoagulants in acute stroke TREATMENT versus CONTROL: death from all causes

\begin{tabular}{|c|c|c|c|c|}
\hline $\begin{array}{l}\text { Trials } \\
\text { anabyeed }\end{array}$ & $\begin{array}{l}\text { Evente/Patients } \\
\text { Treatment Control }\end{array}$ & $\begin{array}{l}\text { Stratified } \\
\text { (O-E) Variance }\end{array}$ & $\begin{array}{l}\text { Odde Ratio and CL } \\
\text { (Treatment : Control) }\end{array}$ & $\begin{array}{l}\text { Odds } \\
\text { reduction } \\
\text { (sd) }\end{array}$ \\
\hline
\end{tabular}

ACUTE PRESUMED ISCHAEMIC STROKE:

HEPARIN TRIALS

$\begin{array}{lcc}\text { Duke }^{19} & 17 / 112 & 8 / 113 \\ \text { CESG }^{20} & 0 / 24 & 3 / 21 \\ \text { MCCarthy }^{21} & 31 / 144 & 53 / 161 \\ \text { MCCarthy }^{22} & 3 / 16 & 5 / 16 \\ \text { Czechanowski }^{23} & 7 / 54 & 12 / 53\end{array}$

Duke $^{24}$

- Subtotal: Standard heparin

Turpie 25

Prins $^{26}$

Sandset ${ }^{27}$

Elias $^{28}$

- Subtotal: LMW Heparin

(data not available)

$58 / 350 \quad 81 / 364$

4/50 5/25

$9 / 30 \quad 4 / 30$

$5 / 52 \quad 1 / 51$

$3 / 15 \quad 3 / 15$

$21 / 147 \quad 13 / 121$

$79 / 497$

$94 / 485$

ORAL ANTICOAGULANT TRIAL

Marshalle

$8 / 26$

$7 / 25$

- Total: lechaemic stroke trials $87 / 523$

$101 / 510$

ACUTE HAEMORRHAGIC STROKE:

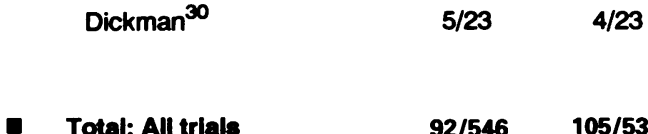

b) Effect of heparin on pulmonary embolism The data on pulmonary embolism (fatal or non-fatal) are given in fig 2 . The $58 \%$ reduction in pulmonary embolism, though substantial, is not conventionally significant.

c) Effect of heparin or warfarin on death from all causes by the end of study period

Allocation to treatment with any type of anticoagulant therapy in acute ischaemic or haemorrhagic stroke was associated with a non-significant $14 \%$ reduction in the odds of death (SD 15, 2p > 0.1) from all causes by the end of scheduled follow up period ${ }^{19-30}$ (fig 3 ). Because of the relatively few deaths, the $95 \%$ confidence intervals were wide and included the possibilities that treatment could be associated with a reduction of perhaps one third or with an increase of about one sixth in the odds

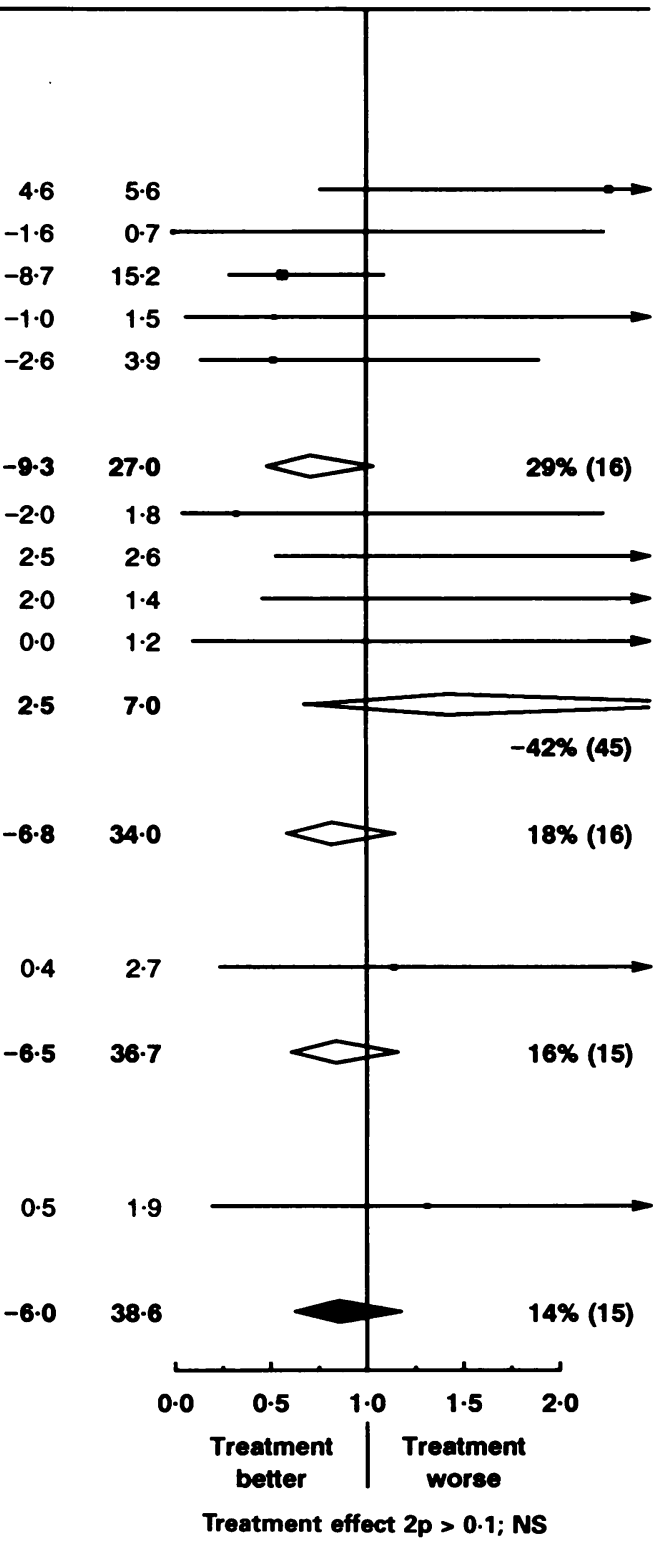

of death. Analysis of the heparin trials in acute ischaemic stroke ${ }^{19-28}$ showed that treatment was associated with a non-significant $18 \%$ reduction (SD $16,2 p>0 \cdot 1$ ) in the odds of death by the end of scheduled follow up period (fig 3). The trial in haemorrhagic stroke ${ }^{30}$ showed a non-significant $31 \%$ increase in the odds of death (SD 84, 2p >0.1, NS). These results are shown in fig 3. Mortality results were not significantly different in trials where heparin was given to patients with CT-confirmed cerebral infarction and in trials where heparin was given without CT. However, the data were wholly inadequate to determine the effect on mortality of a policy of "heparinization without CT"

A separate analysis of the numbers of deaths from all causes during the scheduled treatment period was reported in eight trials. ${ }^{19202325-29}$ 
Figure 4 Apparent effect of heparin on haemorrhagic transformation of the infarct. For explanation of symbols and conventions, see legend to fig 1.
Heparin in acute ischaemic stroke HEPARIN versus CONTROL: haemorrhagic transformation of the infarct

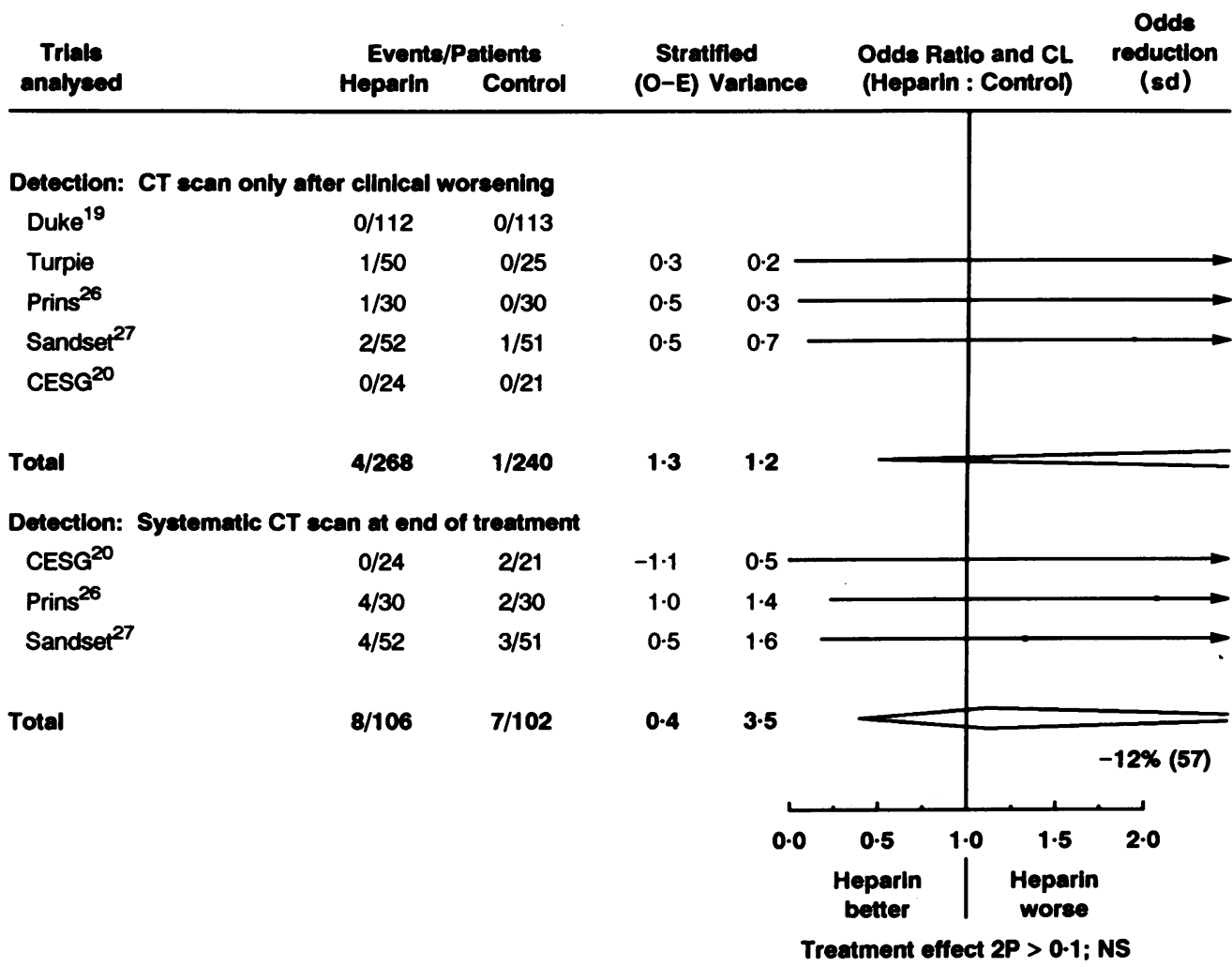

The numbers of deaths were small; $28 / 333$ allocated control vs $32 / 363$ allocated anticoagulants. There was a non-significant $10 \%$ increase in the odds of death (SD 29, $2 \mathrm{p}>0 \cdot 1$, NS) with a very wide confidence interval; consistent with either evidence of a beneficial effect, a harmful effect or no effect at all. Data on cause specific mortality in each treatment group, on recurrent stroke and on disability at six months were not available from the published reports or from the trialists' personal records.

\section{d) Effect of heparin on haemorrhagic} transformation of the cerebral infarct

A relatively unbiased assessment of the effect of antithrombotic treatment on the occurrence of haemorrhagic transformation of the infarct (HTI) would come from studies where all surviving patients have a CT scan at the end of the scheduled treatment period, irrespective of any clinical deterioration. The least biased assessment would be of the effect of treatment on the composite event "HTI detected on routine CT scanning at the end of the scheduled treatment period or fatal haemorrhagic stroke during the scheduled treatment period" (no trials had this as a prespecified analysis). Five trials $^{192025-27}$ reported data on HTI detected by CT scan: CT scan was performed because of clinical deterioration and the results of these trials showed that treatment was associated with a $198 \%$ excess of HTI (SD $165 \%, 2 p$ $>0 \cdot 1$, NS) (fig 4). Analysis restricted to "haemorrhagic transformation on routine scans performed at the end of the scheduled treatment period or fatal haemorrhagic stroke" showed that treatment was associated with a $12 \%$ increase in HTI (SD $56,2 p>0 \cdot 1$, NS) (fig 4).

Trials of antiplatelet agents in acute stroke Of the six trials of antiplatelet therapy in patients with acute ischaemic stroke, the three largest have not been completed. Two of the completed trials did not systematically record data on clinical events ${ }^{31}{ }^{32}$ (they studied laboratory coagulation factors only) and the third was too small to be informative. ${ }^{33}$

\section{Discussion}

Current use of antithrombotic drugs in acute stroke

There is considerable variation in the use of antithrombotic drugs (aspirin or heparin) to treat patients with acute ischaemic stroke. ${ }^{34}$ In a survey of the current treatment of patients with ischaemic stroke, $83 \%$ of US neurologists reported that they had used heparin in such patients over the previous year. ${ }^{34}$ However, only $6 \%$ of the physicians felt that, based on their understanding of the literature, heparin had clearly been shown to be effective in the treatment of patients with acute cerebral infarction. Furthermore, 59\% thought it had not been shown to be effective. ${ }^{34}$ Despite these apparently conflicting opinions, approximately $22 \%$ of patients with ischaemic stroke seen by USA neurologists in the survey were given heparin within the first 24 hours of stroke. ${ }^{34}$ In the Stroke Data Bank, ${ }^{35} 36$ a multicentre project which prospectively collected data on patients with stroke admitted to academic hospitals in the USA, 538 of 1273 patients 
Deep vein thrombosis, pulmonary embolism, death and haemorrhagic transformation of the infarct in randomised trials of heparin in acute ischaemic stroke.

$\begin{array}{cccccc}\text { Proportional reduction : } & 81 \%(8) & 58 \%(46) & 18 \%(16) & -12 \%(57) \\ 2 p & : & <0.00001 & \text { NS } & \text { NS } & \text { NS } \\ \text { Events prevented per 1000: } & 369(98) & 34(86) & 35(142) & -7 \text { (64) }\end{array}$

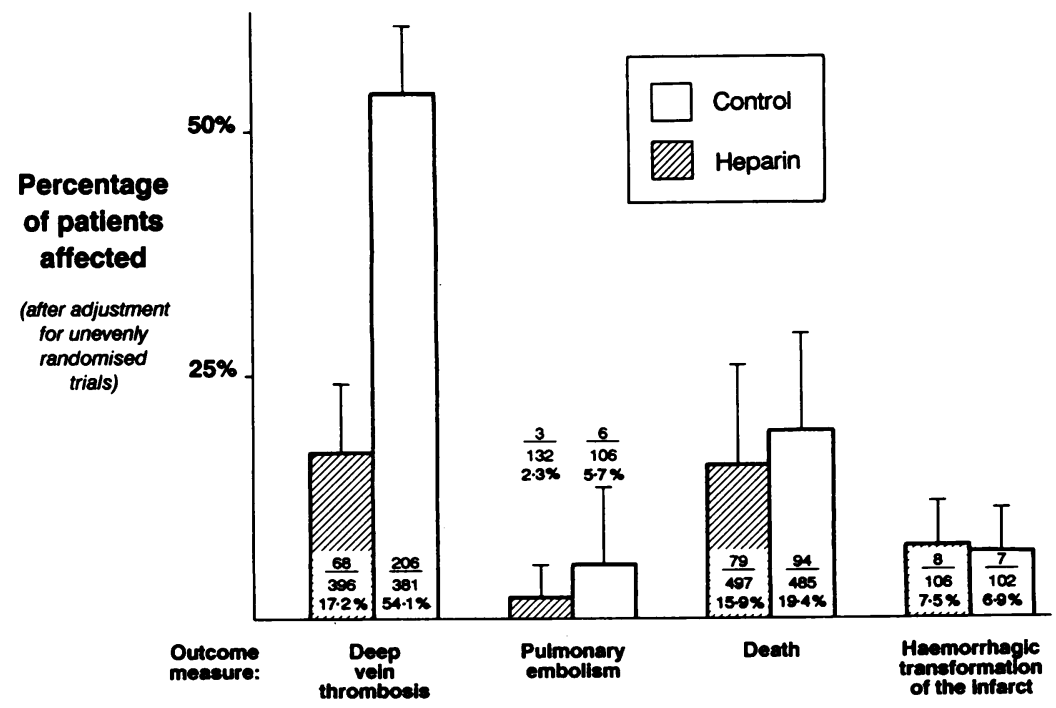

Figure 5 Absolute rates of DVT, pulmonary embolism, death and haemorrhagic transformation of the infarct in patients with presumed or confirmed cerebral infarction. Figures in brackets are standard deviations. fied. Previous reviews have either been informal, with no statistical estimation of typical treatment effects, ${ }^{39-41}$ or did not use accepted statistical methods ${ }^{42}$ or pooled data from trials of acute treatment with trials of long-term secondary prevention. ${ }^{42}$ In the present overview in patients with acute, presumed ischaemic stroke, allocation to heparin therapy was associated with a highly significant $81 \%$ reduction in the odds of DVT. Proportional reductions in DVT were similar with standard heparin, LMW heparin, fixed low-dose regimes and adjusted full-dose regimes. Reductions were similar in patients with acute CT confirmed ischaemic stroke, with presumed ischaemic stroke and with acute haemorrhagic stroke. Heparin had similar effects on DVT in stroke patients as in patients experiencing different types of surgery ${ }^{13}$ and in patients with acute $M{ }^{37}$ In the present overview, the reductions in the absolute risk of DVT were substantial: heparin therapy reduced DVT from $57 \%$ among controls to $15 \%$ among treated patients. There were insufficient events in the present overview to determine whether the reduction in DVT would lead to a reduction in pulmonary embolism (PE) in stroke patients. However, the observed $58 \%$ reduction in $\mathrm{PE}$ with heparin prophylaxis for stroke patients was similar to the results of heparin prophylaxis in surgical patients $(47 \%$ reduction in $\mathrm{PE})^{13}$ and in patients with acute MI (54\% reduction in PE). ${ }^{37}$ The reduction in non-fatal pulmonary embolism with heparin ( $5.7 \%$ reduced to $2 \cdot 3 \%$ ) would suggest that routine heparin thromboprophylaxis for patients with acute stroke might avoid three or four hundred DVTs and perhaps 30-40 pulmonary emboli for every thousand patients treated (fig 5). Should therefore all patients with ischaemic (or, indeed, haemorrhagic) stroke now be given heparin routinely to prevent DVT (and probably pulmonary embolism)? Our conclusion is that they should not because of lack of good data on safety.

Heparin in acute myocardial infarction

As the underlying pathophysiology of acute cerebral infarction and acute myocardial infarction have many features in common, it is useful to review the effects of heparin in acute myocardial infarction. A formal review of twenty four trials of heparin in patients with an acute myocardial infarction by MacMahon et $a l^{37}$ provided clear evidence of benefit; allocation to heparin was associated with a significant $10 \%$ reduction in mortality. In these trials, heparin significantly reduced reinfarction by one fifth and stroke by one half. The heparin regimes tested in about $90 \%$ of patients involved doses of 20000 IU or more daily, given subcutaneously in about half the patients. An overview of two large trials published after McMahon's review (ISIS-3 and GISSI-2) showed that, when subcutaneous heparin is given to patients with acute myocardial infarction who have already received aspirin and a fibrinolytic drug, the benefits of adding heparin may be rather more modest. ${ }^{38}$

Heparin or warfarin in acute stroke; are they effective?

There has been no formal overview of the studies in acute stroke which we have identi-

\section{Is heparin safe in acute stroke?}

There is considerable uncertainty about the effect of therapy on the risk of death; therapy was associated with an $18 \%$ reduction in the odds of death (equivalent to the avoidance of perhaps 20 to 40 deaths per 1000 patients treated), but the upper $95 \%$ confidence interval was compatible with heparin leading to an increase in the odds of death by one sixth. Thus the present data cannot exclude the possibility that routine heparin therapy might cause an excess of perhaps 40 deaths for every 1000 patients treated. The second reason is that the data were wholly inadequate to assess the effect of heparin on the risk of disabling or fatal haemorrhagic transformation of cerebral infarction.

\section{Heparin dosage}

There is also uncertainty about the optimum dose of heparin. Whilst low dose subcutaneous heparin is effective in the prevention of venous thromboembolism, ${ }^{13}$ higher dose subcutanehourly, are more effective in the prevention of ous heparin regimes, such as 12500 units 12 
thrombi in the arterial circulation, as assessed by the effects on left ventricular thrombus formation in acute myocardial infarction. ${ }^{910}$ Inhibition of formation or propagation of thrombi in cerebral arteries holds the promise of preventing stroke progression, and possibly even reducing cerebral infarct size, with a reduction in the subsequent neurological impairment and disability. However, several studies have suggested a higher risk of bleeding complications with the higher dose heparin regimes. ${ }^{1011}$ A study by Turpie directly compared 12500 units of heparin subcutaneously twice a day with 5000 units subcutaneously in patients with acute myocardial infarction, ${ }^{9}$ the risk of serious bleeding in the two treatment groups was very similar (1/112 for high dose heparin, 1/109 for low dose heparin). Whilst the observed effect (a 3\% reduction in serious bleeds) was not conventionally significant, confidence intervals were very wide and included the possibility that the higher dose was associated with a 15-fold excess of serious bleeds. These data are wholly inadequate to assess any excess bleeding risk associated with the higher heparin dose. In acute ischaemic stroke, when haemorrhagic transformation or frank intracerebral bleeding can often be fatal or disabling, a randomised trial is clearly needed, not just to determine whether heparin is effective, but also to determine the relative safety and efficacy of the two doses: the balance of risks and benefits may be quite different for different doses.

Antiplatelet therapy in acute ischaemic stroke If a policy of routine early aspirin therapy was shown to be equally effective and safe in the treatment of acute cerebral infarction as it is in the treatment of acute myocardial infarction, ${ }^{4}$ such a policy might lead to the avoidance of perhaps 20 to 40 deaths for every thousand acute ischaemic stroke patients treated. Widespread use of immediate aspirin therapy for patients with acute ischaemic stroke in the USA and the European Community might therefore avoid several thousand early deaths from stroke each year; perhaps 300000 deaths over the next decade. If aspirin were to be used on this scale, it would need to be supported by particularly reliable evidence of safety and efficacy from large trials. No such trials exist. Whilst heparin is promising, aspirin is equally, or perhaps even more promising as an antithrombotic regime, as it is even cheaper and simpler to administer than fixed-dose subcutaneous heparin.

Design considerations for trials capable of confirming or refuting the effects of antithrombotic therapy in acute ischaemic stroke suggested by present review

Firstly, the trial should be large: ISIS-2 was able to provide particularly clear evidence on the efficacy and safety of two widely practicable treatments for acute myocardial infarction because of its size: 1820 deaths occurred in the randomised 17187 patients. ${ }^{4}$ The results were statistically reliable and allowed the analysis of clinically important subgroups, thus it was possible to determine whether or not treatment was effective, but also for whom treatment was most likely to be effective. For example, stratified analyses clearly demonstrated that increasing delay in the start of fibrinolytic therapy was associated with progressive reduction in efficacy. The strength of evidence provided by the trial persuaded many clinicians to change their clinical practice and so both aspirin and streptokinase are now part of the routine care of patients with acute $\mathrm{MI} .^{43}$ The use of a $2 \times 2$ factorial design allowed each agent (aspirin and streptokinase) to be compared separately, and in combination, against control with the same sample size that would be required to compare one agent against control; the factorial design is statistically efficient and allows "two questions to be answered for the price of one". The trial was extremely simple in design, involving clinicians in little extra work, and thus enabled busy clinicians in district general hospitals to collaborate in the trial. The treatment was tested on a scale appropriate to its future use (ie in millions of patients with acute myocardial infarction worldwide). Similar, large, simple trials of aspirin and subcutaneous heparin which recruit the number of patients appropriate to the likely scale of their future use (millions of stroke patients worldwide) are now needed. In this context, trials which enroll a few tens of thousands of patients with acute ischaemic stroke seem appropriate. For example, a study which recruited just 20000 patients with acute ischaemic stroke (that is, about half the size of ISIS-3), in which two week mortality was $12 \%$ in patients allocated control and $10 \%$ in patients allocated heparin could provide reliable evidence on the mortality effects: if an $18 \%$ (SD4) reduction in the odds of death were observed, it would be highly statistically significant and the $95 \%$ confidence intervals would be fairly precise (11-25\% reduction). Perhaps more importantly, reliable analyses of medically important subgroups would also be possible (for example, whether benefit was substantially different in: patients started on treatment within six hours of onset, compared with those started later, in patients with cerebral infarction due to major cerebral vessel occlusion, compared with small vessel lacunar strokes, in patients aged over 75 compared with younger patients). Such analyses would give useful guidance to clinicians on whether treatment is particularly beneficial (or particularly hazardous) in certain categories of patient.

Trials in acute ischaemic stroke must also measure outcome in terms of survival free of severe disability (as in the Italian haemodilution trial $^{44}$ ) to ensure that treatment does not increase the proportion of patients surviving in a disabled state. No data on survival free of severe disability were available for the present review. Several trials conforming to these requirements are now planned or in progress (tables 1 and 2).

\section{Conclusion}

For patients with acute ischaemic stroke there 
is therefore uncertainty about the balance of risks (disabling or fatal haemorrhagic transformation of cerebral infarcts and other bleeds) and potential benefits (reductions in cerebral infarct size, reduction in DVT and pulmonary embolism, all contributing to reduced early mortality and reduced disability in long-term survivors) from early antithrombotic therapy with either heparin or aspirin. On present evidence therefore a policy of routine antithrombotic therapy in the acute phase of stroke cannot be justified until the results of current large trials are available.

This report could not have been compiled without the collaboration of the trialists who undertook these trials and, in several instances, provided extra data to enable appropriate analyses to be performed. Dr P A G Sandercock and Mr J Slattery are supported by a grant from the Medical Research Council. Dr R I Lindley is supported in part by grants from The Clinical Trials Service Unit, Oxford, Lilly Pharmaceuticals and the Stroke Association. The authors gratefully acknowledge the the Stroke Association. The authors gratefully acknowledge the assistance of the Clinical Secretariat of the Antiplatelet Trialists
Collaboration in identifying all truly randomised trials of Collaboration in identifying all truly randomised trials of
antiplatelet therapy in the early treatment of acute ischaemic antiplatelet therapy in the early treatment of acute ischaemic
stroke. The figures were produced by Jon Godwin and Pamela stroke. The figures were produced by Jon Godwin
Bell in the Clinical Trials Service Unit, Oxford.

The International Stroke Trial (co-principal investigators Dr Peter Sandercock and Professor Charles Warlow) will begin in early 1993. Anyone who would like to collaborate in the trial should write to Dr Peter Sandercock, Neurosciences Trials Unit, Western General Hospital, Edinburgh EH4 2XU, UK (telephone UK(44)-(0)31-343-6639, Fax UK(44)(0)31-332-5150).

1 Broderick JP, Phillips SJ, Whisnant JP, O'Fallon WM, Bergstralh EJ. Incidence rates of stroke in the eighties: the end of the decline in stroke? Stroke 1989;20:577-82.

2 Homer D, Whisnant JP, Schoenberg BS. Trends in the incidence rates of stroke in Rochester, Minnesota, since incidence rates of stroke in Roches

3 Bamford J, Sandercock P, Dennis M, Burn J, Warlow C. A prospective study of acute cerebrovascular disease in the community: the Oxfordshire Community Stroke Project1981-1986 2. Incidence, case fatality and overall outcome at one year of cerebral infarction, primary intracerebral haemorrhage and subarachnoid haemo rhage. I Neurol Neurosurg Psychiatry 1990;53:16-22.

4 ISIS-2 Collaborative Group. Randomised trial of intravenous streptokinase, oral aspirin, both, or neither among 17,187 cases of suspected acute myocardial infarction: ISIS-2. Lancet 1988;2:349-60.

5 The RISC group. Risk of myocardial infarction and death during treatment with low dose aspirin and intravenous heparin in men with unstable coronary artery disease. heparin in men with unst

6 Theroux P, Ouimet H, McCans J, et al. Aspirin, heparin, or both to treat acute unstable angina. $N$ Engl $\mathcal{f} \mathrm{Med}$ 1988:319:1105-11.

7 Cairns JA. Clinical trials of antiplatelet drug therapy in acute myocardial infarction, unstable angina, and aortocoronary bypass surgery. Cardiovasc Clin 1987;18: $231-46$.

8 Lewis HD, Davis JW, Archibald DG, et al. Protective effects of aspirin against acute myocardial infarction and death in men with unstable angina. Results of a Veterans Administration Cooperative Study. N Engl f Med 1983;309: 396-403.

9 Turpie AGG, Robinson JG, Doyle DJ, et al. Comparison of high-dose with low-dose subcutaneous heparin to prevent high-dose with low-dose subcutaneous heparin to prevent left ventricular mural thrombosis in patients with acute
transmural anterior myocardial infarction. $N$ Engl $f$ Med transmural anterio

10 The SCATI (Studio sulla calciparina nell'angina e nella trombosi venticolare nell'infarto) group. Randomised controlled trial of subcutaneous calcium-heparin in acute myocardial infarction. Lancet 1989;2:182-6.

11 Gruppo Italiano per lo studio della sopravvivenza nell'infarto miocardico. GISSI-2: a factorial randomised trial of alteplase versus streptokinase and heparin versus no heparin among 12,490 patients with acute myocardial infarction. Lancet 1990;336:65-71.

12 Salzman EW, Harris WH. Acetylsalicylic acid for the prevention of venous thromboembolic disease in surgical patients. In: Barnett HJM, Hirsh J, eds. Acetylsalicylic acid: new uses for an old drug. New York: Raven Press, 1982:225-34.

13 Collins R, Scrimgeour A, Yusuf S, Peto R. Reduction in fatal pulmonary embolism and venous thrombosis by perioperMed 1988;318:1162-73.

14 Yusuf S, Wittes J, Friedman L. Overview of results of randomized clinical trials in heart disease. I. Treatments following myocardial infarction. $¥ A M A$ 1988;260: 2088-93.

15 Yusuf S, Collins R, Peto R. Why do we need some large, simple randomised trials? Stat Med 1984;3:409-20.
16 Yusuf S, Peto R, Lewis J, Collins R, Sleight P. Beta blockade during and after myocardial infarction: an overview of the randomised trials. Prog Cardiovasc Dis 1985;27:335-71.

17 Antiplatelet Trialists' Collaboration. Secondary prevention of vascular disease by prolonged antiplatelet treatment. of vascular disease by prolonged antiplatelet treatment. 320-31.

18 Early Breast Cancer Trialists' Collaborative Group. Treatment of early breast cancer, vol I: worldwide evidence 1985-1990. Oxford: Oxford University Press, 1990.

19 Duke RJ, Bloch RF, Turpie AGG, Trebilcock R, Bayer N. Intravenous heparin for the prevention of stroke progression in acute part
$1986 ; 105: 825-8$

20 Cerebral Embolism Study Group. Immediate anticoagulation of embolic stroke: a randomised trial. Stroke 1983;14:668-76.

21 McCarthy ST, Turner J. Low-dose subcutaneous heparin in the prevention of deep-vein thrombosis and pulmonary
emboli following acute stroke. Age Ageing 1986;15:84-8.

22 McCarthy ST, Robertson D, Turner JJ, Hawkey CJ. Low dose heparin as a prophylaxis against deep-vein thrombodose heparin as a prophylaxis against deep-vein
sis after acute stroke. Lancet 1977;2:800-1.

23 Czechanowski B, Heinrich F. Prophylaxe venoser thrombosen bei frischem ischamischem zerebrovaskularem insultdoppel-blindstudie mit heparin-dihydergot. Dtsch Med Wochenschr 1981;106:1254-60.

24 Duke RJ, Turpie AG, Bloch RF, Trebilcock RG. Clinical trial of low-dose subcutaneous heparin for the prevention of stroke progression: natural history of acute partia stroke and stroke-in-evolution. In: Reivich M, Hurtig HI, eds. Cerebrovascular disease. New York:Raven Press, 1983:399-405.

25 Turpie AG, Levine MN, Hirsh J, et al. Double-blind randomised trial of Org 10172 low-molecular-weight heparinoid in prevention of deep-vein thrombosis in heparinoid in prevention of deep-vein

26 Prins MH, Gelsema R, Sing AK, van Heerde LR, den Ottolander GJH. Prophylaxis of deep venous thrombosis with a low-molecular-weight heparin (Kabi 2165/Frag$\mathrm{min}$ ) in stroke patients. Haemostasis 1989;19:245-50

27 Sandset PM, Dahl T, Stiris M, Rostad B, Scheel B Abildgaard U. A double-blind and randomised placebocontrolled trial of low molecular weight heparin once daily to prevent deep-vein thrombosis in acute ischaemic stroke. Seminars in thrombosis and hemostasis 1990;(suppl 16):25-33.

28 Elias A, Milandre L, Lagrange G, et al. Prevention of deep venous thrombosis of the leg by a very low molecular weight heparin fraction (CY 222) in patients with hemiplegia following cerebral infarction: a randomized pilot study (30 patients). Rev Med Interne 1990; pilot study

29 Marshall J, Shaw DA. Anticoagulant therapy in acute cerebrovascular accidents: a controlled trial. Lancet 1960;995-8.

30 Dickmann U, Voth E, Schicha $H$, Henze T, Prange $H$, Emrich D. Heparin therapy, deep vein thrombosis and pulmonary embolism after intracerebral haemorrhage. Klin Wochenschr 1988;66:1182-3.

31 Utsumi $\mathbf{H}$. Evaluation of the utility of ticlopidine, an antiplatelet agent, for acute cerebral infarction (Sanof technical report). Manchester: Sanofi, 1990.

32 Joseph R, Welch KM, D'Andrea G. Effect of therapy on platelet activating factor-induced aggregation in acute platelet activating factor-induced

33 Ciuffetti G, Aisa G, Mercuri M, Lombardini R, Paltriccia $R$, Neri C, Senin U. Effects of ticlopidine on the neurologic outcome and the hemorheologic pattern in the postacute phase of ischaemic stroke: a pilot study. Angiology 1990;41:505-11.

34 Marsh EE, Adams HP, Biller J, Wasek P, Banwart K, Mitchell V, Woolson R. Use of antithrombotic drugs in the treatment of acute ischaemic stroke. A survey of neurologists in practice in the United States. Neurology
$1989 ; 39: 1631-4$.

35 Foulkes MA, Wolf PA, Price TR. The stroke data bank; design, methods and baseline characteristics. Stroke 1988;19:547-54.

36 Hier DB, Foulkes MA, Swiontoniowski M, et al. Stroke recurrence within 2 years after ischaemic infarction. Stroke 1991;22:155-61.

37 MacMahon S, Collins R, Knight C. Reduction in major morbidity and mortality by heparin in acute myocardial morbidity and mortality by heparin in

38 ISIS-3 Collaborative Group. ISIS-3 A randomized comparison of streptokinase vs tissue plasminogen activator vs anistreplase and of aspirin plus heparin vs aspirin alone among 41,299 cases of suspected acute myocardial infarction. Lancet 1992;339:753-70.

39 Levine MN, Hirsh J. Haemorrhagic complications of longterm anticoagulant therapy for ischaemic cerebral vascular disease. Stroke 1986;17:111-16.

40 Levine MN, Hirsh J. Haemorrhagic complications of anticoagulant therapy. Semin Thromb Hemost - 1986, 12:39-57.

41 Levine $M$. An overview of clinical trials of low molecular weight heparin fractions. Agressologie 1989;30:347-8.

42 Jonas $S$. Anticoagulant therapy in cerebrovascular disease: review and meta-analysis. Stroke 1988;19:1043-8.

43 Collins R, Julian D. British Heart Foundation Surveys (1987 and 1989) of United Kingdom treatment policies for acute myocardial infarction. Br Heart $\mathcal{f} 1991$; 66(3):250-5.

44 Italian Acute Stroke Study Group. The Italian hemodilution trial in acute stroke. Italian Acute Stroke Study Group. Stroke 1987;18:670-6. 